\title{
Knowledge, Attitude and Practice of General Practitioners on Circumcision and Its Complications in the District Hospitals of the Center Region
}

\author{
Binyom Pierre René1, Mbassi Achille1, Biwolé Biwolé Daniel'2, Kamnang Arthur Joël1, \\ Zare Cyprien ${ }^{3}$, Gueswendé Larba Herman Belemlilga ${ }^{3}$, Nassirou Yabré ${ }^{3}$, Namory Keita ${ }^{3}$, \\ Biwole Sida Magloire1
}

\author{
${ }^{1}$ Higher Institute of Medical Technology of Nokolondom, Yaoundé, Cameroon \\ ${ }^{2}$ Medical Faculty of Yaoundé University, Yaoundé, Cameroon \\ ${ }^{3}$ Department of General and Visceral Surgery, Sourô Sanou University Teaching Hospital, Bobo-Dioulasso, Burkina Faso \\ Email: p.r.binyom@gmail.com,drmbassi@yahoo.com,daniel.biwole@fmsb-uy1.com, arthur.kamnang@gmail.com, \\ zcyprien@yahoo.fr, h.belemlilga@yahoo.fr
}

How to cite this paper: René, B.P., Achille, M., Daniel, B.B., Joël, K.A., Cyprien, Z., Belemlilga, G.L.H., Yabré, N., Keita, N. and Magloire, B.S. (2021) Knowledge, Attitude and Practice of General Practitioners on Circumcision and Its Complications in the District Hospitals of the Center Region. Open Journal of Urology, 11, 509-517. https://doi.org/10.4236/oju.2021.1112051

Received: September 27, 2021

Accepted: December 26, 2021

Published: December 29, 2021

Copyright $\odot 2021$ by author(s) and Scientific Research Publishing Inc. This work is licensed under the Creative Commons Attribution International License (CC BY 4.0).

http://creativecommons.org/licenses/by/4.0/

\begin{abstract}
Background: The complication rate of circumcision in medical settings is between $0.4 \%$ and $2.0 \%$. Circumcision accidents constituted $2.0 \%$ of urological emergencies at the Yaoundé Central Hospital. Aim: To assess the level of knowledge, attitudes and practices of general practitioners on circumcision and its complications in Central Region District Hospitals. Population and Methods: We conducted a multicenter descriptive cross-sectional study the CAP (Knowledge, Attitudes and Practices) type. Which took place from March 9 to June 30, 2021 (16 weeks). We included 138 physicians. The variables collected were: socio-demographic characteristics, knowledge about circumcision and its complications, attitudes towards circumcision and its complications, practices towards circumcision and its complications. Results: In our study, the median age of the study population was 29 years, the sex ratio $(\mathrm{M} / \mathrm{F})$ was 0.8 . The median ideal age to perform circumcision was 12 months. In our study, $94.9 \%$ of general practitioners clearly identified bleeding disorders as a contraindication for circumcision. The material needed to be used to perform a circumcision was ignored by $81.2 \%$ of general practitioners. The global knowledge assessment showed that $68.9 \%$ of participants had unsatisfactory knowledge about circumcision and its complications. Before circumcision, $91.3 \%$ general practitioners first recommended effective disinfection of the operating field, and $83.3 \%$ used sterile equipment. Faced with a hemorrhage, $61.6 \%$ of general practitioners proposed surgical exploration in the face of rebellious bleeding. $60.2 \%$ of general practitioners had bad
\end{abstract}


attitudes towards circumcision and its complications. In our study, $49.2 \%$ of the general practitioners questioned did not know the normal procedure for performing a circumcision. Forty-one (29.7\%) general practitioners had never performed a circumcision. The median occurrence of a complication during circumcision was 2 times. Bleeding was the most common early postoperative complication $(89.2 \%)$ in general practitioner practice during circumcision. Conclusion: The majority of general practitioners have not received formal education on circumcision.

\section{Keywords}

Knowledge, Attitude, Practice, Circumcision, Posthectomy

\section{Introduction}

In its most common form, the term circumcision (posthectomy) designates the total or partial removal of the foreskin [1]. It is practiced on all continents and according to the WHO $30.0 \%$ of the world's male population over the age of fifteen is circumcised [2]. Posthectomy is a surgical procedure indicated for surgical conditions or for the reduction of transmission of Human Immunodeficiency Virus (HIV) from women to men [3] [4] [5]. But most often, it is performed as part of a religious, ethnic or social ritual by personnel of various qualifications: traditional circumcisers, nurses, doctors [2] [6] [7]. Still classified under the rubric of "minor surgery", circumcision carries immediate health risks and can lead to serious complications. The complication rate in medical settings is between $0.4 \%$ and $2.0 \%$. On the other hand, outside any medical environment, the complication rate is much higher and could reach $35.0 \%$ to $48.0 \%$ [2]. Owon'Abessolo et al. in 2020 found that circumcision accidents constituted 2.0\% of urological emergencies at the Yaoundé Central Hospital [8]. The heavy surgical procedures indicated for the correction of complications justify that circumcision, if it is not reserved for expert hands, should be supervised when it is performed [9]. No similar study has been published. Thus, in order to establish a framework for better training of people empowered to perform circumcision; in order to establish a framework for a better training of people authorized to perform circumcision, we carried out this study in order to assess the level of knowledge, attitudes and practices of general practitioners on circumcision and its complications in Central Region District Hospitals.

\section{Population and Methods}

We conducted a multicenter descriptive cross-sectional study of the CAP (Knowledge, Attitudes and Practices) type which took place from March 9 to June 30, 2021 (16 weeks). Our study covered 25 District Hospitals of the Central Region chosen by lot. The study population were general practitioner, out of 189 physicians. We included 138 physicians present and having agreed to participate in 
the study. This recruitment was done according to the non-probability sampling model; and the data were collected in four stages: The first being based on the selection by lot of 25 district hospitals out of 29 present. The second stage was based on the distribution of work by district hospital; 5 working days in some and 3 working days in others. The third step included the list of general practitioners and the fourth step, the strategy of inclusion of the study populations. The variables collected were: socio-demographic characteristics: age, sex, region of origin, marital status, religion, number of years of service; knowledge about circumcision and its complications; attitudes towards circumcision and its complications; practices regarding circumcision and its complications. We entered the data in Census and Survey Processing System (CSPro) version 7.5 analysis software and analyzed using Statistical Package for Social Science (SPSS) version 23.0.

\section{Results}

\subsection{Socio-Demographic Characteristics}

Table showing the distribution of the study population by age group, sex, region of origin and number of years of service in age group.

\begin{tabular}{|c|c|c|}
\hline Variables & $\begin{array}{l}\text { Number } \\
(\mathrm{N}=138)\end{array}$ & $\begin{array}{c}\text { Percentage } \\
(\%)\end{array}$ \\
\hline \multicolumn{3}{|c|}{ Age groups (in years) } \\
\hline$[25-30]$ & 85 & 61.6 \\
\hline$[30-35]$ & 48 & 34.8 \\
\hline$\geq 35$ & 5 & 3.6 \\
\hline \multicolumn{3}{|c|}{ Sex } \\
\hline male & 64 & 46.4 \\
\hline female & 74 & 53.6 \\
\hline \multicolumn{3}{|c|}{ Region of origin } \\
\hline Center & 52 & 37.7 \\
\hline West & 30 & 21.7 \\
\hline Littoral & 12 & 8.7 \\
\hline South & 12 & 8.7 \\
\hline East & 10 & 7.2 \\
\hline Far North & 8 & 5.8 \\
\hline North-West & 5 & 3.6 \\
\hline South-West & 4 & 2.9 \\
\hline Adamaoua & 3 & 2.2 \\
\hline North & 2 & 1.4 \\
\hline \multicolumn{3}{|c|}{ Number of years of service in age groups (in years) } \\
\hline$<2$ & 19 & 13.8 \\
\hline$[2-4]$ & 88 & 63.8 \\
\hline$[4-6]$ & 27 & 19.6 \\
\hline$\geq 6$ & 4 & 2.9 \\
\hline
\end{tabular}


In our study, the median age of the study population was 29 years with an interquartile range of [ 28 - 30] years; a minimum of 25 years and a maximum of 38 years; and more than half (61.6\%) were between 25 and 30 years old. The sex ratio $(\mathrm{M} / \mathrm{F})$ was 0.8 in favor of the female sex. The region mainly represented was that of the Center (37.7\%).

General practitioners had a median professional length of service of 3 years with an interquartile range of 2 to 3 years; a minimum of 1 year and a maximum of 8 years; and more than half (63.8\%) had between two and four years of service.

\subsection{Knowledge Assessment}

The majority (99.3\%) of general practitioners knew how to define circumcision. The median ideal age to perform circumcision was 12 months with a minimum of 0.25 months and a maximum of 144 months. Eighty-two (59.6\%) general practitioners thought it was better to perform circumcision after the neonatal period (after one month of life). One hundred and one (73.2\%) revealed that they had acquired their knowledge from colleagues. In our study, $94.9 \%$ of general practitioners clearly identified bleeding disorders as a contraindication for circumcision. $73.9 \%$ and $63 \%$ respectively identified anemia and skin infection in the penis as a contraindication. The material needed to be used to perform a circumcision was ignored by $81.2 \%$ of general practitioners. In our study, $58.0 \%$ general practitioners revealed that complications from circumcision were very common in their work environment. The most well-known complication of circumcision $(94.9 \%)$ by general practitioners was hemorrhage, followed by infection (87\%), and amputation traumatic glans $(75.4 \%)$. The global knowledge assessment showed that $68.9 \%$ of participants had unsatisfactory knowledge about circumcision and its complications. Table 1 presents the overall assessment of general practitioners.

\subsection{Attitude Assessment}

Forty-three (31.2\%) general practitioners rarely explained the procedure to parents before performing the procedure. Before circumcision, $91.3 \%$ general practitioners first recommended effective disinfection of the operating field, and $83.3 \%$ used sterile equipment. Faced with a hemorrhage, $61.6 \%$ of general practitioners proposed surgical exploration in the face of rebellious bleeding. Faced with an infection, $63.8 \%$ recommended debridement of necrotic and infected tissues under anesthesia. Faced with an amputation of the glans when performing a circumcision, $29.7 \%$ thought that an attempt should be made to re-implant the distal end of the organ. After circumcision, $87.7 \%$ general practitioners first offered counseling relating to compliance with care in the postoperative period. The overall assessment of attitudes is presented in Table 2. It shows that $60.2 \%$ of general practitioners had bad attitudes towards circumcision and its complications. 
Table 1. Global assessment of the knowledge of general practitioners.

\begin{tabular}{ccccc}
\hline Levels of knowledge & \multicolumn{2}{c}{$\begin{array}{c}\text { Points to answer } \\
\text { Maximum score } \mathrm{n}=7\end{array}$} & \multicolumn{2}{c}{$\begin{array}{c}\text { All respondents } \\
\mathbf{N}=138\end{array}$} \\
\hline & $\begin{array}{c}\text { Score obtained Score obtained } \\
\text { (n) }\end{array}$ & $\begin{array}{c}\text { Workforce } \\
\text { (\%) }\end{array}$ & $\begin{array}{c}\text { Percent } \\
(\%)\end{array}$ \\
\hline Bad & $0-1$ & $0-24$ & 13 & 9.5 \\
Insufficient & $2-3$ & $25-49$ & 82 & 59.4 \\
Average & $4-5$ & $50-69$ & 41 & 29.7 \\
Good & $6-7$ & $70-100$ & 2 & 1.4 \\
\hline
\end{tabular}

Table 2. Global assessment of the attitudes of general practitioners.

\begin{tabular}{ccccc}
\hline \multirow{2}{*}{ Level of attitudes } & \multicolumn{2}{c}{ Points to answer } & \multicolumn{2}{c}{ All respondents } \\
& Maximum score $\mathbf{n}=7$ & \multicolumn{2}{c}{ N=138 } \\
\hline & $\begin{array}{c}\text { Score obtained Score obtained } \\
\text { (n) }\end{array}$ & $\begin{array}{c}\text { Workforce } \\
(\%)\end{array}$ & $\begin{array}{c}\text { Percent } \\
(\%)\end{array}$ \\
\hline Bad & $0-1$ & $0-24$ & 20 & 14.5 \\
Wrong & $2-3$ & $25-49$ & 63 & 45.7 \\
Approximate & $4-5$ & $50-69$ & 52 & 37.7 \\
Fair & $6-7$ & $70-100$ & 3 & 2.1 \\
\hline
\end{tabular}

\subsection{Practice Evaluation}

In our study, $49.2 \%$ of the general practitioners questioned did not know the normal procedure for performing a circumcision. Forty-one $(29.7 \%)$ general practitioners had never performed a circumcision. Of these, $80.5 \%$ (33) said they were not fit or able to perform circumcision. Forty-five (46.4\%) general practitioners never requested a preoperative assessment before performing a circumcision. Seventy-six (78.4\%) general practitioners never requested a pre-anesthetic consultation before performing a circumcision. Seventy-four (76.3\%) general practitioners performed the circumcision with the assistance of an assistant. Thirty-six (37.1\%) general practitioners were unaware of the technique they used during a circumcision. Eighty-two (84.6\%) general practitioners used local anesthesia to perform a circumcision. Seventy (72.2\%) performed circumcision usually in the hospital in a minor surgery room. Forty-two (43.3\%) performed less than 5 circumcisions per year. The median number of circumcisions performed per year was 5 times with an interquartile range of 3 to 20 times; a minimum of 3 times and a maximum of 20 times. Sixty-nine (71.1\%) used the antiseptics for the dressing. Fifty-nine (60.8\%) performed the dressing 2 days after circumcision. The median time to dressing was 2 days with an interquartile range of 2 to 3 days; a minimum of 1 day and a maximum of 7 days. Eighty-seven (89.7\%) general practitioners performed the dressing in the minor surgery room. Thirty-seven (38.1\%) had already had a complication when performing a circumcision. The median occurrence of a complication during cir- 
cumcision was 2 times with an interquartile range of 1 to 3 times; a minimum of 1 time and a maximum of 5 times. Bleeding was the most common early postoperative complication $(89.2 \%)$ in general practitioner practice during circumcision. Deformation of the penis was the most common late postoperative complication (18.9\%) in general practitioner practice during circumcision. Seventeen (46.9\%) of the general practitioners who had had a complication while performing the circumcision were slightly uncomfortable in managing the bleeding. Thirty-three (89.2\%) were very uncomfortable in the management of traumatic glans amputation as well as urethral fistula. In total, $47.5 \%$ of the participants had an inadequate practice with regard to circumcision and its complications. The evaluation of the participants' practice is presented in Table 3.

\section{Discussion}

The majority of general practitioners who participated in the study were women. This reflects the sex ratio at the level of higher education in Cameroon. On the other hand, according to Ekenze et al., in Nigeria, there were more men (85.3\%) than women [10]. The young age of the participants explained why professional seniority was reduced with a median of 3 years.

Almost all of the participants knew how to define circumcision. However, the contraindications for circumcision were not sufficiently known. The et al. found that no participant could correctly identify all the contraindications for circumcision [11]. The majority of general practitioners recommended having the child circumcised after the neonatal period. Machmouchi et al. in their series in Saudi Arabia in 2007 found that circumcision at 5 months resulted in significantly fewer serious complications than circumcision in the neonatal period [12]. However, circumcision in the neonatal period is favored by Warner [13]. According to Mouafo in Cameroon in 2012, the variability of age can be explained by the fact that in African countries, the age of circumcision is dependent on the habits and customs of the populations. Thus in our environment, circumcision is practiced late in early childhood and constitutes a sacred act which confers on the child the recognition of his belonging to the male sex, and the anticipation of a flawless sexuality to the child adulthood [14]. Complications of circumcision are very common in our study. This corroborates what Sylla found, who explained this by the fact that circumcision was still carried out in the vast majority

Table 3. Global assessment of the practices of general practitioners.

\begin{tabular}{ccccc}
\hline Level of practices & \multicolumn{2}{c}{$\begin{array}{c}\text { Points to answer } \\
\text { Maximum score = 8 }\end{array}$} & \multicolumn{2}{c}{$\begin{array}{c}\text { All respondents } \\
\text { N = 138 }\end{array}$} \\
\hline & $\begin{array}{c}\text { Score obtained Score obtained } \\
(\mathbf{n})\end{array}$ & $\begin{array}{c}\text { Workforce } \\
(\mathbf{N})\end{array}$ & $\begin{array}{c}\text { Percent } \\
(\%)\end{array}$ \\
\hline Harmful & $0-2$ & $0-24$ & 8 & 8.2 \\
Inadequate & $3-4$ & $25-49$ & 46 & 47.5 \\
Adequate & $5-8$ & $50-100$ & 43 & 44.3 \\
\hline
\end{tabular}


of cases, in a traditional way or by unqualified paramedical agents. The knowledge of general practitioners about circumcision and its complications was insufficient. This knowledge came mainly from colleagues and not from basic or continuing education. While, Ekenze et al. in Nigeria in 2015 found that $36.2 \%$ had received formal training in circumcision [10]. In the USA, Le et al. revealed that $44.0 \%$ had received formal training [11]. Demaria et al. emphasized the importance of proper training and follow-up [15].

Our study shows that the general practitioners questioned rarely explained the procedure to parents before performing the procedure. According to the American Academy of Pediatrics in 2012, clinicians should explain the potential benefits and risks of circumcision before circumcision is performed [16]. The attitude of doctors to a complication was often inadequate. Surgical exploration for intractable bleeding was not the rule for all participants. Surgical management for an infection or glans amputation was not known to all general practitioners. The majority of the doctors questioned proposed firstly to do a "counseling" relating to the respect of care in the postoperative period, then to carry out the dressing only in the hospital, and finally to prohibit the application of vegetable substances on the circumcision wound. This is consistent with what the American Academy of Pediatrics recommended in 2012 [16]. Overall, the majority of respondents had bad attitudes towards circumcision and its complications, which reflects their lack of initial and continuing training.

Half of the participants could not describe the normal procedure for performing a circumcision. A significant proportion of physicians performing circumcision were unaware of the technique they had used. According to Ekenze et al. a significant proportion of physicians faced with circumcision felt that their training was not optimal enough [10]. The average number of circumcisions performed per year was low. According to Demaria et al. 48.0\% of non-surgeons performed more than 50 circumcisions per year [15]. This can be explained by the fact that in our environment circumcision is much more practiced by paramedics and traditional circumcisers in out-of-hospital settings. Local anesthesia was the most used. Dorsal penile nerve block with ring block is the most effective technique for providing anesthesia during neonatal circumcision [17]. In our survey, $38.1 \%$ of general practitioners who performed circumcision had already had a complication at least once. In a series including 29 cases of circumcision complication, Diabaté et al. had objectified $7.0 \%$ of circumcisions made by doctors [18]. According to the participants, $16.2 \%$ were comfortable during the management of the bleeding, none were comfortable during the treatment of the stenosis of the urethral meatus versus $63.0 \%$ and $10.0 \%$ respectively of nonsurgeons according to Demaria et al. in Canada [15]. According to Mouafo et al. in his study in 2016 on circumcision accidents at the gynecology-obstetrics and pediatric hospital in Yaoundé, the accidents generated by the untimely practice of circumcision in our environment are numerous and serious enough for circumcision to be considered an act surgery in its own right [9]. Faced with the observation of inadequate practices vis-à-vis circumcision and its complications, 
the time has come to study the proposals of authors such as Dieth et al. in Côte d'Ivoire in 2008 which would consist of integrating circumcision into the programs of medical students [19]. Because of the limitation of our study, we were unable to go through all the 28 District Hospitals of the Central Region. The study is limited to 25 District Hospitals in the Central Region. In addition, nothing guarantees the objectivity of the answers given by the participants of this study. Similar studies should be carried out in other regions of Cameroon with a larger sample size to generalize the results.

\section{Conclusion}

At the end of our study, it appears that the majority of general practitioners have not received formal education on circumcision. This can result in a lack of knowledge of contraindications, complications of circumcision, the performance of inadequate surgery and the lack of satisfactory pre and postoperative care.

\section{Conflicts of Interest}

The authors declare no conflicts of interest regarding the publication of this paper.

\section{References}

[1] Aynaud, O., Malka, G. and Devincenti, I. (1998) Pathologie de la verge. Masson, Paris.

[2] OMS \& UNAIDS (2007) Male Circumcision Global Trends and Determinents of Prevalence, Safety and Acceptability. OMS, Génève.

[3] Auvert, B., Taljaard, D., Lagarde, E., Sobngwi-Tambekou, J., Sitta, R. and Puren, A. (2005) Randomized, Controlled Intervention Trial of Male Circumcision for Reduction of HIV Infection Risk: The ANRS 1265 Trial. PLoS Medecine, 11, 298. https://doi.org/10.1371/journal.pmed.0020298

[4] Bailey, C., Moses, S., Parker, C., Agot, K., Maclean, I., Krieger, J., et al. (2007) Male Circumcision for HIV Prevention in Young Men in Kisumu, Kenya: A Randomized Controlled Trial. The Lancet, 9562, 643-656. https://doi.org/10.1016/S0140-6736(07)60312-2

[5] Gray, H., Kigozi, G., Serwadda, D., Makumbi, F., Watya, S., Nalugoda, F., et al. (2007) Male Circumcision for HIV Prevention in Young Men in Rakai, Uganda: A Randomized Trial. The Lancet, 9562, 657-666. https://doi.org/10.1016/S0140-6736(07)60313-4

[6] Chaim, J., Pinhas, M., Binyamini, J., Hardak, B., Meir, D. and Mor, Y. (2005) Complications de la circoncision en Israël: Une enquête multicentrique d'un an. Israel Medical Association Journal, 6, 368-370.

[7] Okeke, L., Asinobi, A. and Ikuerowo, O. (2006) Epidemiology of Complications of Male Circumcision in Ibadan, Nigeria. BMC Urology, 1, 1-3. https://doi.org/10.1186/1471-2490-6-21

[8] Owon'Abessolo, P., Mayopa, C., Mekeme, J., Fouda, J., Biyouma, M., Dongmo, G., et al. (2020) Urgences Urologiques: Aspects Épidémiologiques, Cliniques et Thérapeutiques à l'Hôpital Central de Yaoundé. Health Science Disease, 8, 52-55.

[9] Mouafo, F., Ditope, J., Fadi, S., Nyanit, B., Mbouche, L. and Andze, O. (2016) 
Aspects anatomocliniques et thérapeutiques des accidents de la circoncision à l'hôpital Gynéco-obstétrique et pédiatrique de Yaoundé (HGOPY): À propos de 15 cas. Revue Africaine de Chirurgie et Spécialités, 3, 15-18.

[10] Ekenze, S., Ugwu, J. and Onumaegbu, O. (2015) Evaluation of Neonatal Circumcision Training for Resident Doctors in a Developing Country. Journal of Pediatric Urology, 5, 263. https://doi.org/10.1016/j.jpurol.2015.03.017

[11] Le, B., Mickelson, J., Gossett, D., Kim, D., Stoltz, R., York, S., et al. (2010) Formation en résidanat en matière de circoncision néonatale: une étude pilote et l'évaluation des besoins. The Journal of Urology, 4, 1754-1757.

https://doi.org/10.1016/j.juro.2010.03.077

[12] Machmouchi, M. and Alkhotani, A. (2007) La circoncision néonatale est-elle judicieuse? European Journal of Pediatric Surgery, 4, 266-269.

https://doi.org/10.1055/s-2007-965417

[13] Warner, E. (1981) Benefits and Risk of Circumcision. Canadian Medical Association Journal, 125, 967-976.

[14] Mouafo, F. (2012) Les accidents de la circoncision à Yaoundé, Cameroun: À propos de cinq observations cliniques. Progrès en Urologie, 1, 63-66.

https://doi.org/10.1016/j.purol.2011.06.003

[15] DeMaria, J, Abdulla, A, Pemberton, J, Raees, A, and Braga, L. (2013) Les médecins pratiquant des circoncisions néonatales sont-ils bien formés? Canadian Urology Association Journal, 7-8, 260-264. https://doi.org/10.5489/cuaj.200

[16] American Academy of Pediatrics Task Force on Circumcision (2012) Male Circumcision. Pediatrics, 3, 756-785. https://doi.org/10.1542/peds.2012-1990

[17] Sumit, D., Kourosh, A., Luis, H. and Peter, A. (2018) Ligne directrice de l'Association canadienne d'urologie sur les soins du prépuce normal et la circoncision néonatale chez les nourrissons canadiens. Canadian Urologic Association Journal, 2, 76-99.

[18] Diabaté, I., Ondo, C., Diallo, H., Thiam, M. and Ba, A. (2016) Prise en charge des complications de la circoncision. Sexologies, 3, 169-175. https://doi.org/10.1016/j.sexol.2016.10.003

[19] Dieth, A., Moh, N., Fiogbe, M., Yao, K., Tembely, S., Bandre, E., et al. (2008) Accidents de circoncision chez l'enfant à Abidjan: Côte d'Ivoire. Bulletin de la Société de Pathologie Exotique, 4, 314-315. https://doi.org/10.3185/pathexo3134 